\title{
REVIEW \\ Global maps of non-traumatic spinal cord injury epidemiology: towards a living data repository
}

\author{
PW New ${ }^{1,2}$, RA Cripps $^{3}$ and B Bonne Lee ${ }^{4,5}$
}

Study design: Literature review.

Objectives: Globally map non-traumatic spinal cord injury (NTSCI) incidence, prevalence, survival, level of injury and aetiology. Propose a research framework for NTSCl prevention and launch a repository of NTSCI data.

Setting: Initiative of the International Spinal Cord Society Prevention Committee.

Methods: Literature search of Medline and Embase (1959-June 2011). Relevant articles in any language regarding adults with NTSCI were included. Stratification of information about incidence and prevalence into green/yellow/orange/red data quality 'zones' and comparisons between World Health Organisation (WHO) regions and countries.

Results: Three hundred and seventy-seven abstracts reviewed-45 of these from 24 countries in 12 of the 21 WHO global regions had relevant information. Only one publication had survival data. Prevalence data for NTSCl existed for only two countries, India (prevalence of 2310/million population, Kashmir region) and Canada (prevalence of 1 120/million population). The incidence rates for WHO regions were: Asia Pacific, high income 20/million population/year; Australasia (26/million population/year); Western Europe median of 6/million population/year; North America, high income median 76/million population/year (based on poor-quality studies); and Oceania 9/million population/year. Developed countries tended to have a higher proportion of cases with degenerative conditions and tumours. Developing countries, in comparison, tended to have a higher proportion of infections, particularly tuberculosis and HIV, although a number also reported tumours as a major cause.

Conclusions: Insufficient survival, prevalence and incidence data are a predominant finding of this review. The piecemeal approach to epidemiological reporting of NTSCI, particularly failing to include sound regional population denominators, has exhausted its utility. Minimum data collection standards are required.

Spinal Cord (2014) 52, 97-109; doi:10.1038/sc.2012.165; published online 15 January 2013

Keywords: non-traumatic spinal cord injury; spinal cord diseases; epidemiology; incidence; prevalence; aetiology

\section{INTRODUCTION}

It is well documented that damage to the spinal cord can arise from many causes other than trauma, often referred to as non-traumatic spinal cord injury (NTSCI). ${ }^{1,2}$ Compared with traumatic spinal cord injury (TSCI), there are relatively few publications on NTSCI. It is anticipated that with the aging of the global population in coming decades the incidence of NTSCI will increase substantially. ${ }^{3}$ Therefore, studies of the incidence, aetiology, prevalence and survival following NTSCI will be vital to assist in health-care service planning and delivery, and will facilitate the development of preventive strategies where these are possible.

The International Spinal Cord Society (ISCoS) Prevention Committee has presented information on TSCI using global maps to provide direction for international collaboration regarding TSCI injury prevention. ${ }^{4}$ These enhanced mapping techniques are just as relevant for NTSCI. The project described here is part of a world-wide spinal cord injury (SCI) mapping project that is being undertaken by the Prevention Committee of ISCoS.
The NTSCI subsection of the ISCoS Prevention Committee aims to:

1. Disseminate NTSCI data through global maps for Spinal Cord Injury epidemiology (http://iscos.org.uk/page.php?content=67).

2. Create partnerships within ISCoS to facilitate development of strategies for primary and secondary prevention of NTSCI.

3. As with the TSCI maps, ${ }^{4}$ establish an electronic data repository accessible through the ISCoS website to enable conversion of key demographic information to an easily interpretable and updatable map of global trends in NTSCI.

It is intended that this work continues as an ongoing project that will be open to contributions of published and unpublished data to assist the ISCoS Prevention Committee and other organisations in the task of NTSCI prevention.

The primary aim of this project was to report the results of a comprehensive literature review and to compile global maps

\footnotetext{
${ }^{1}$ Epworth-Monash Rehabilitation Medicine Unit, Southern Medical School, Monash University, Melbourne, Victoria, Australia; ${ }^{2}$ Spinal Rehabilitation Unit, Rehabilitation Services, Caulfield Hospital, Alfred Health, Caulfield, Victoria, Australia; ${ }^{3}$ School of Medicine (Prevention, Promotion and Primary Health Care Cluster), Flinders University, Adelaide, South Australia;

${ }^{4}$ Spinal Medicine Department, Prince of Wales Hospital, Sydney, New South Wales, Australia and ${ }^{5}$ Neuroscience Research Australia (NEURA), University of New South Wales, Sydney, Australia

Correspondence: Dr PW New, Spinal Rehabilitation Unit, Caulfield Hospital, Alfred Health, 260 Kooyong road, Caulfield, Victoria 3162, Australia

E-mail: p.new@cgmc.org.au
}

Received 23 February 2012; revised 11 July 2012; accepted 11 July 2012; published online 15 January 2013 
summarising the epidemiology of NTSCI, with a focus on the incidence, prevalence, level of injury, aetiology and survival. Secondary aims were: (a) to propose a research framework for health-care management strategies that could potentially prevent some types of NTSCI and improve NTSCI survival, and (b) to make suggestions for improving the epidemiological data collection and reporting of NTSCI studies.

\section{MATERIALS AND METHODS}

The literature searches of New and Sundararajan ${ }^{3}$ and Wyndaele $^{5}$ were repeated without language restriction using search phrases (exploded): 'Epidemiology of spinal cord injury'; 'Prevalence of spinal cord injury'; 'Incidence of spinal cord injury'; 'nontraumatic'; 'non-traumatic'; and 'spinal cord damage' using the Medline and Embase databases as part of the global mapping project first described in Cripps et al. ${ }^{4}$ In addition, the reference lists from articles identified in the literature search were reviewed to help identify other potentially relevant sources of information. The articles about NTSCI identified in New and Sundararajan ${ }^{3}$ were also reviewed. All publications regarding adults from 1959 up to June 2011 were included. The personal libraries of the authors were also reviewed to identify additional potential publications. Publications covering paediatric NTSCI were excluded and will be the subject of a separate project.

The quality of information and level of national representation in the identified publications was appraised using a grading system to guide readers in interpreting the results and conclusions reached. Each paper's quality (Table 1) was graded as high $(\mathrm{H})$, moderate $(\mathrm{M})$ or low (L) using the methodology described by Lee et al. ${ }^{6}$ in this issue. Where no incidence data were available, the most representative and best-quality studies covering the other epidemiological parameters were included, and the overall quality of the publication and how the information was collected was noted. The initial quality grading was performed by two of the authors independently (RAC and PWN). The results were compared and any conflicting assessments $(n=7)$ were then reviewed by the third author (BBL), who made the final determination.

World Health Organisation (WHO) global regions were utilised to allow epidemiologically similar countries to be compared. ${ }^{7}$ Maps using SCI incidence and aetiological data were developed for WHO global regions and countries within these regions using mapping and graphical techniques developed by Myriad Editions (http://www.myriadeditions.com/health). Data were divided into four broad zones of information quality (Box 1). The best ranked studies for each WHO region determined the colour coding used in the global map. Where possible, comparisons of incidence, prevalence, level of injury, aetiology and survival were planned between WHO regions and countries.

The classification of NTSCI has not been standardised until recently, when ISCoS and American Spinal Injury Association (ASIA) approved the International Non-traumatic Spinal Cord Injury Data Sets. ${ }^{8}$ This present project used the classification of NTSCI from the NTSCI Data Sets at the first two levels, with some categories collapsed or omitted, as recommended, because of the absence or rarity of cases. ${ }^{8}$ The use of the classification in these global maps is proof of concept of how aetiology data can be represented using the classification.

\section{RESULTS}

The abstracts of 377 publications were reviewed and 45 reports from 24 countries in 12 of the 21 WHO global regions were included with information on the incidence, prevalence, survival, level of injury and aetiology of NTSCI. ${ }^{3,9-54}$ The country/region, observation period, data sources, handling of merged data and rating of quality are summarised in Table 1. Publications identified were primarily from peer-reviewed journals and a few governmental reports. Studies were prospective and retrospective and used data from spinal registries, population registries, hospital data (admission and discharge data) and health surveys.
No country had data that were graded green or yellow. Orange Zone data were only available for North America, high income (Canada), Australasia (Australia) and Western Europe (Denmark, Israel, Italy, Netherlands and Spain). Median values of country data were used for mapping WHO global regions and countries where there was more than one result.

\section{Global incidence and aetiology of non-traumatic SCI}

There was a paucity of quality population-based incidence data on NTSCI. The incidence, neurological level and aetiology of NTSCI by WHO region and year of publication are shown in Table 2. Global maps of NTSCI epidemiological outcomes (1959-2011) are presented by WHO global regions (Figure 1) and countries (Figure 2).

\section{Asia pacific, high income}

This WHO global region's profile is based on an epidemiological survey conducted in the Okayama Prefecture located in the western region of Honshu, Japan. ${ }^{9}$ The incident rate of NTSCI was 20 per million population per year. A high rate of degenerative deformity of the spine (59\%) was reported and accounted for $76 \%$ of the tetraplegic cases. Given the age profile of Japan, this is not unexpected. Tumours were also common in this group (19\%).

\section{Asia, south}

Only Indian data were available for this WHO global region and was based on three studies, from Bangalore, Karnataka and Kashmir. ${ }^{10,12,53}$ High rates of tuberculosis were reported in Bangalore (26\%), Karnataka (25\%) and Kashmir (38\%). Tumours were surprisingly high in Bangalore (29\%) and Karnataka (27\%).

\section{Australasia}

Data for this WHO global region were only available from Australia. The incidence rate is consistent across a range of studies using different methodologies, and estimated to be around 26/million adults/year. ${ }^{16}$ The most common causes were tumour, degenerative and vascular conditions.

\section{Europe, western}

In this WHO global region, data were available from eight countries (Denmark, ${ }^{22}$ France, ${ }^{23}$ Germany, ${ }^{54}$ Israel, ${ }^{25}$ Italy, ${ }^{28}$ Netherlands, ${ }^{31}$ Scotland ${ }^{32}$ and Spain $^{33}$ ). The median incidence rate of NTSCI for this region was 6 NTSCI per million population per year. High rates of tumours and degenerative conditions were reported (25\% and 32\% medians, respectively), quite likely influenced by the age profile of the Western European population. Spina bifida was reported as a cause of NTSCI in Spain, Italy (both 5\%) and Denmark (2\%). Myelitis was lower in Israel (7\%) and higher in Denmark (14\%) and Italy (23\%).

\section{North Africa/Middle East}

Very few published articles were found for this WHO global region. Two retrospective studies from Turkey were located, from Ankara and Istanbul. ${ }^{35,36}$ Spinal tumours and degenerative causes of NTSCI were the most commonly diagnosed conditions. Tumours and degenerative conditions were slightly higher in Ankara (29\% for both causes) than in Istanbul (22\% and $25 \%$, respectively). Inflammatory conditions were common in Ankara (23\%) and in Istanbul (20\%). Six percentage of NTSCI cases reported in Istanbul were spina bifida.

\section{North America, high income}

In this WHO global region, an estimated Canadian NTSCI incidence rate of 68 NTSCI per million population per year was reported 


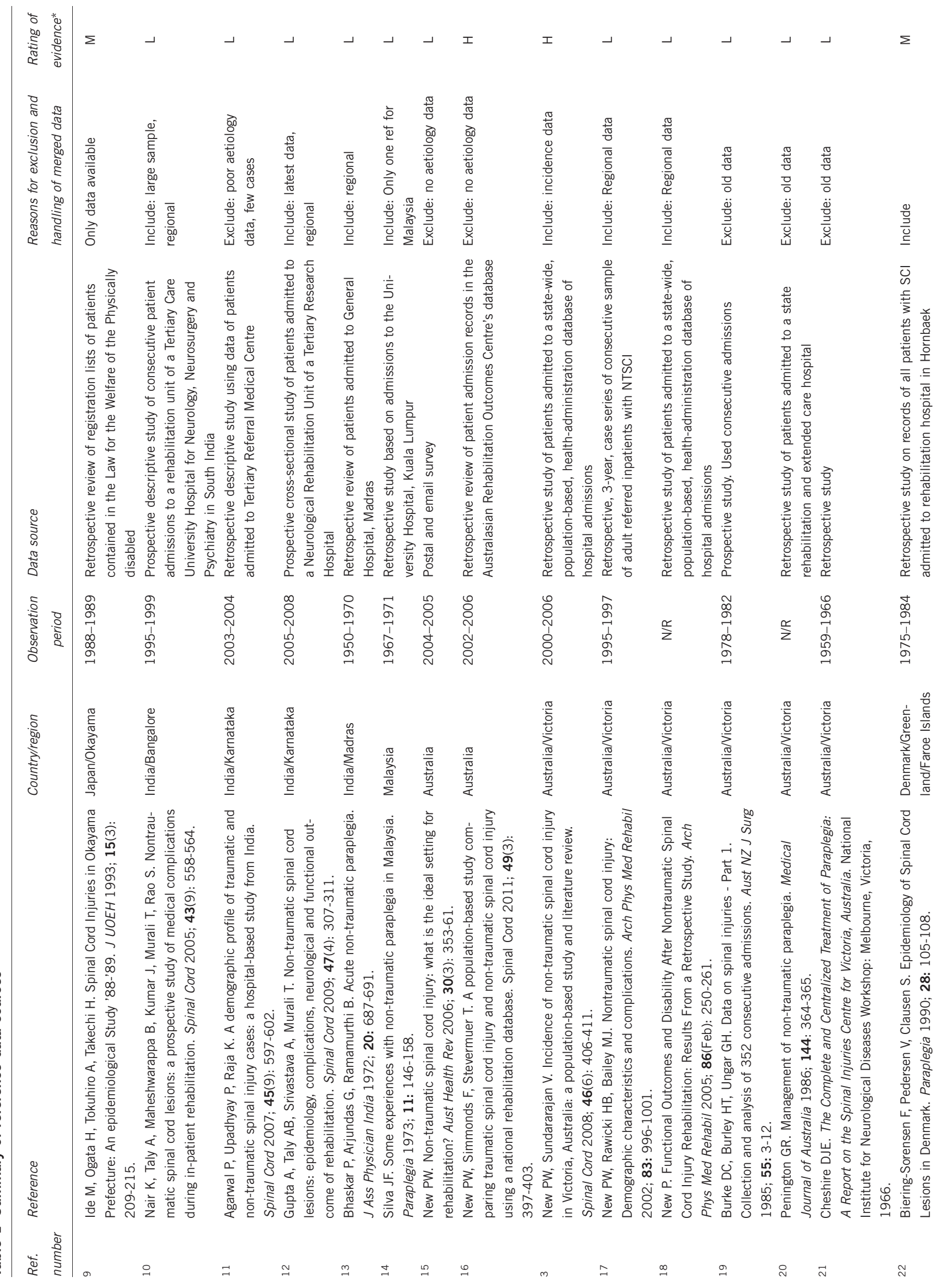




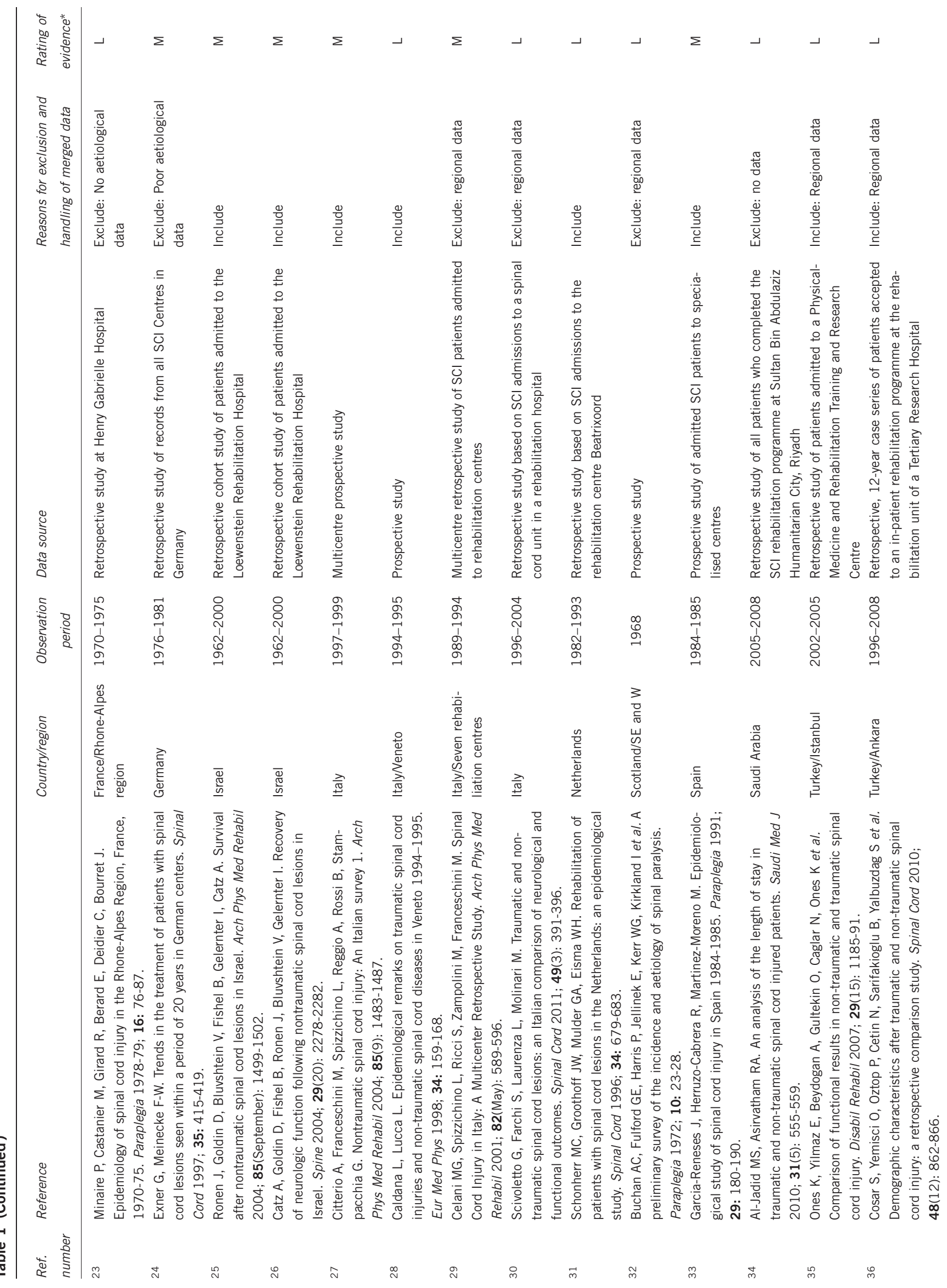




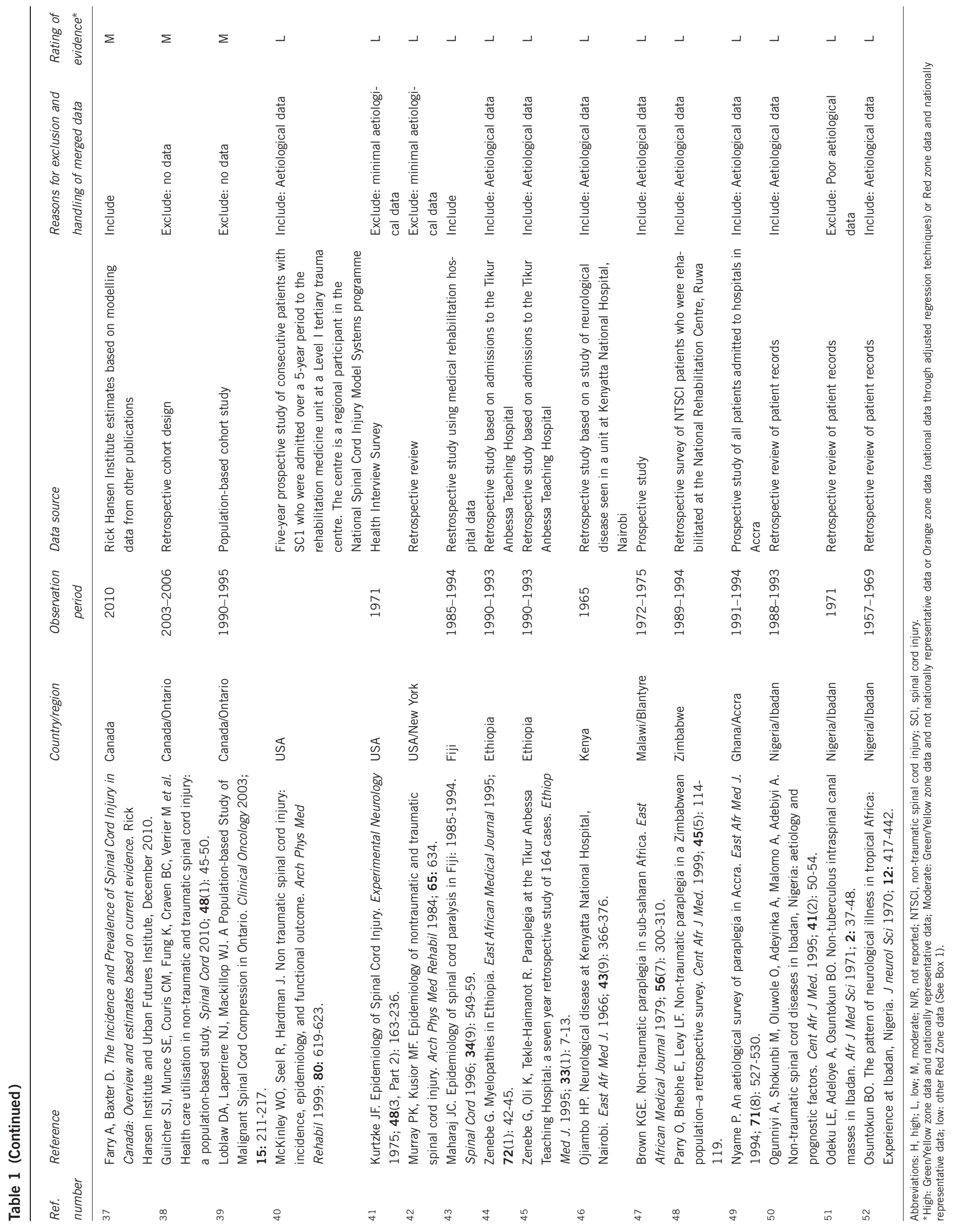




\section{Box 1 Zones of Information*}

Green zone: used a prospective spinal cord injury registry (PSCIR) or population health registry (including population registries linked or able to be linked to health and/or mortality data).

Yellow zone: partial coverage of region or country by PSCIR or population health registry.

Orange zone: Extrapolated data (not directly collected through a formal registry but derived from multiple sources with documented assumptions). Dependent on the assumptions and methods used, caution needs to be made in interpreting this data.

Red zone: no PSCIR or population health registry data. Available information is considered to be of insufficient quality to make between global region or country comparisons on the basis of incidence.

*Incidence data are rated on NTSCI map 1 using these colours.

by the Rick Hansen Institute in 2010, with this being calculated by population modelling and extrapolation techniques. ${ }^{37}$ No aetiological causes of NTSCI were reported in this publication. For the United States, only two reports on incidence were identified - a health survey conducted by the National Centre for Health Statistics in $1971^{41}$ and an abstract of a study conducted in New York. ${ }^{42}$ These rates were 80 and 52 NTSCI per million population per year, respectively. A 5-year prospective study in a Level 1 trauma centre of a Regional SCI Model System ${ }^{40}$ indicated that proportionally spinal stenosis and tumours were common $(54 \%$ and $26 \%$, respectively) and myelitis was low (5\%).

\section{Oceania}

One Fijian study was available for this WHO global region. ${ }^{43}$ The incident rate was 9 NTSCI per million population per year. Tumourrelated NTSCI was low (9\%) and the most frequent cause was infection and the unknown categories ( $32 \%$ and $52 \%$, respectively).

\section{Sub-Saharan Africa, East}

In this WHO global region, published information was available for Ethiopia, ${ }^{44,45}$ Kenya $^{46}$ and Malawi. ${ }^{47}$ Tuberculosis was a major cause of NTSCI in all of these countries. Tuberculosis was highest in Kenya and Malawi (33\% in both countries) and lower in Ethiopia (20 and $27 \%$ ). HIV-related NTSCI was common in Ethiopia (17\%). HIV was not reported for Kenya or Malawi as these papers were published before the emergence of HIV. Tumour-related NTSCI cases were highest in Kenya (33\%), Malawi (25\%) and Ethiopia (22\%). Myelitis was low in Ethiopia (4\%) and Malawi (7\%).

\section{Sub-Saharan Africa, Southern}

Zimbabwean data were the only data available for this WHO global region. ${ }^{48}$ Tumours and tuberculosis-related NTSCI cases were high (28\% and $27 \%$, respectively). Transverse myelopathy accounted for $11 \%$ of the NTSCI cases.

\section{Sub-Saharan Africa, West}

Ghanan and Nigeria data were available for this WHO global region. ${ }^{49-52}$ Tuberculosis-related NTSCI was relatively common in both Ghana and Nigeria (30\% and 25\%, respectively). The proportion of neoplastic NTSCI and myelitis was similar in both countries (about $15 \%$ and $12 \%$, respectively).

\section{Global prevalence of non-traumatic SC}

Prevalence data for NTSCI were located for only two countries, India and Canada. Indian prevalence data of 2310 NTSCI per million population were from the region of Kashmir, ${ }^{53}$ and not national prevalence. The Canadian result of $1120 /$ million population is Orange Zone quality extrapolated from other studies; however, this was the only available national estimate. ${ }^{37}$ The lack of additional studies of NTSCI prevalence limits the usefulness of these statistics for this report. They remain, however, the only currently available estimates (Table 3).

\section{Global survival of NTSCI}

Survival data for people with NTSCI are extremely limited, with only one study identified. ${ }^{25}$ An Israeli study of 1085 patients with NTSCI admitted between 1962 and 2000 reported a median survival of 24 years. Survival was significantly affected by aetiology of lesion, age, gender, severity of lesion, decade of lesion onset and was generally shorter with higher-level lesions. The cumulative mortality was $0.6 \%$ at the first year, $6 \%$ at 5 years and $16 \%$ after 10 years. The mortality risk for patients with disk protrusion, spinal stenosis and benign tumours (majority of tumours) was lower than for patients with myelitis or multiple sclerosis. ${ }^{25}$

\section{DISCUSSION}

There tended to be more reports of better quality from high-income countries compared with medium- and low-income countries. Regarding aetiology, there were clear trends apparent from the available information. Developed countries tended to have a higher proportion of cases with degenerative conditions and tumours causing NTSCI. Developing countries, in comparison, tended to have a higher proportion of infections, particularly tuberculosis and HIV, although it was interesting that a number also reported tumours as a major cause. Irrespective of setting (country or WHO region), NTSCI is much more likely to cause paraplegia. The incidence varied widely across the WHO global regions, and the extremely limited data on prevalence and survival prevented comparisons.

One interesting finding was that given Western Europe has an aged population, the incidence of NTSCI reported was very low compared with other developed regions. We cannot explain this low incidence, and its veracity will be tested by improved regional data reporting standards.

There are poorer-quality epidemiological data on NTSCI than there are for TSCI. One reason for this may be that many spinal registries only include TSCI or have very poor capture of NTSCI. Therefore, data based on these registries underestimate NTSCI. Furthermore, many traditional Spinal Cord Injury Units or Rehabilitation Centres have been established with a TSCI focus and often exclude NTSCI, or subgroups with these disorders. Despite the higher incidence of NTSCI compared with TSCI in some regions, ${ }^{3,37}$ there is a reported bias against NTSCI patients being able to access specialist SCI rehabilitation services. ${ }^{15}$ We believe that this selection bias increases the likelihood of poor-quality data collection regarding these patients because NTSCI patients managed in non-specialist units are less likely to be reported to SCI registries, and if they are, the staff may not have the necessary skills or expertise (for example, AIS grading) to do this accurately. Most clinicians are probably aware of the need for regional SCI statistics. Given the paucity of quality data on NTSCI, it is very likely that clinicians lack the systems and financial resources to undertake the required data collection. Failure to refer patients with NTSCI to a specialised centre, or lack of resources in the specialised centres to accept referrals, makes this task more difficult unless 


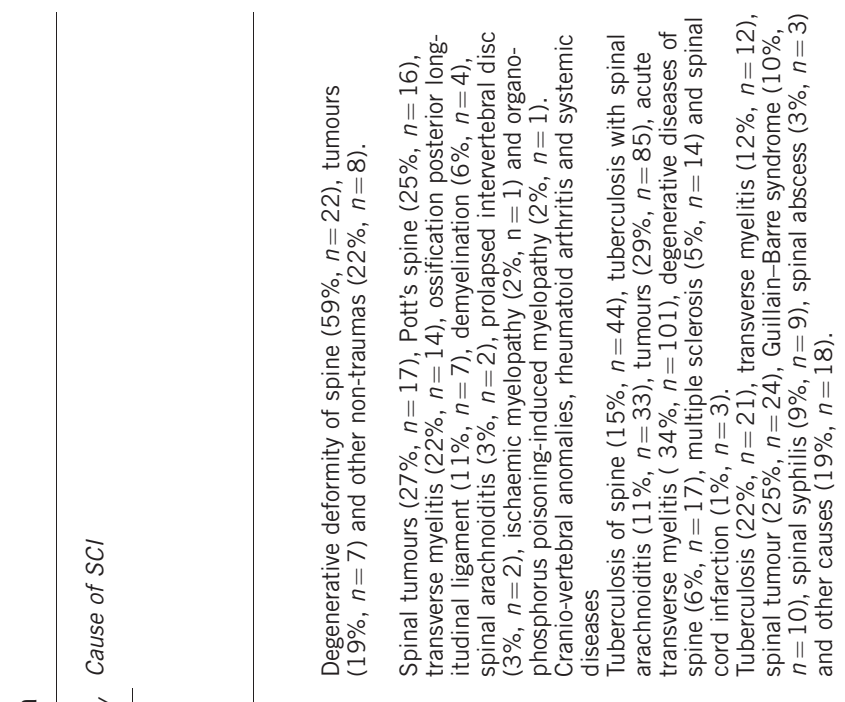

ลำ

III $=\dot{\pi}$

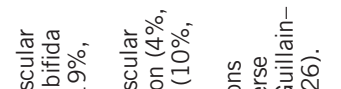

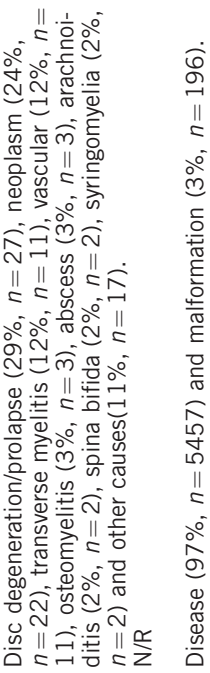

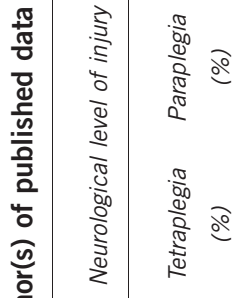

๗ำ ㅇำ $\stackrel{\infty}{\circ}$

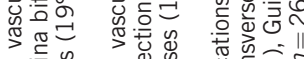

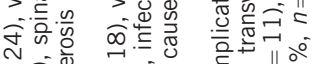

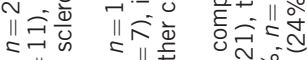

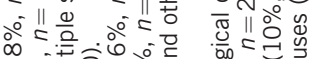

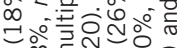

क होता

舟-

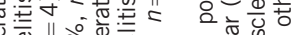

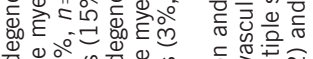

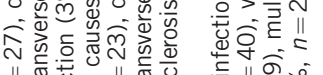

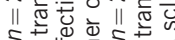

00.0

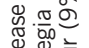

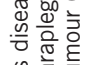

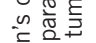

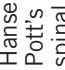

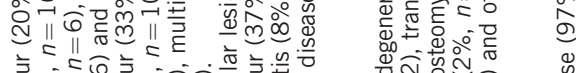

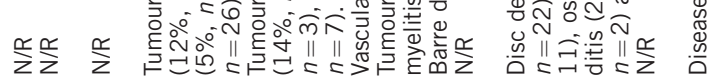

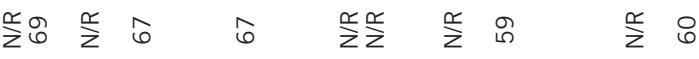

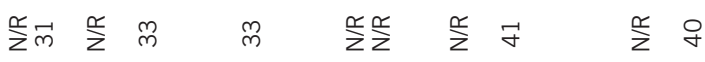

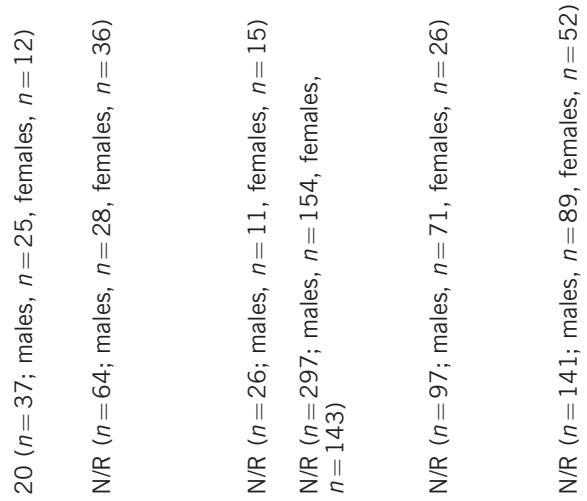

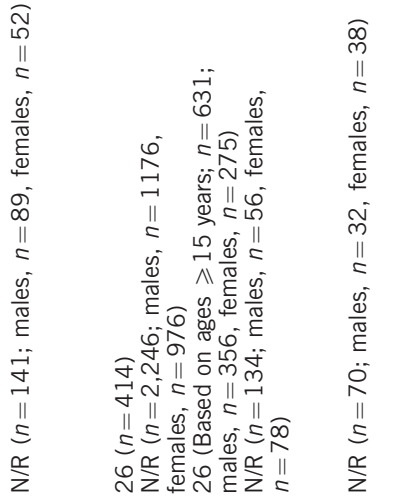

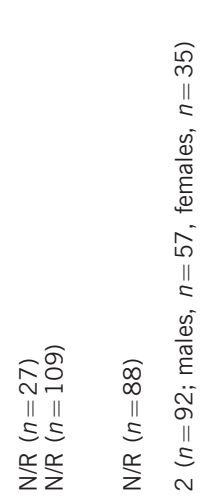

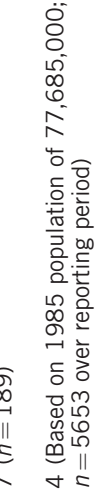

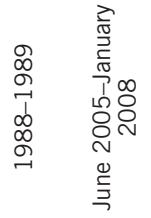

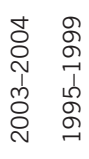

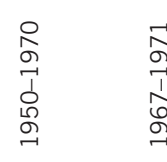

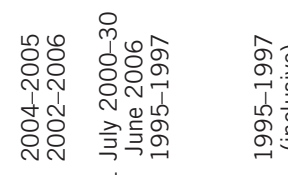

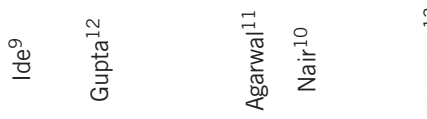

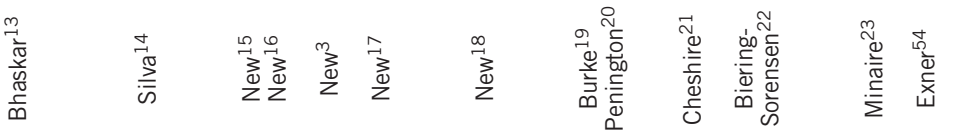

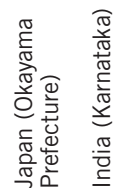

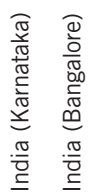

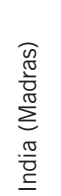

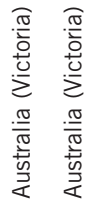

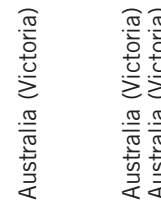

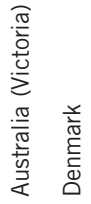

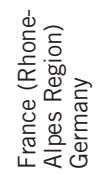




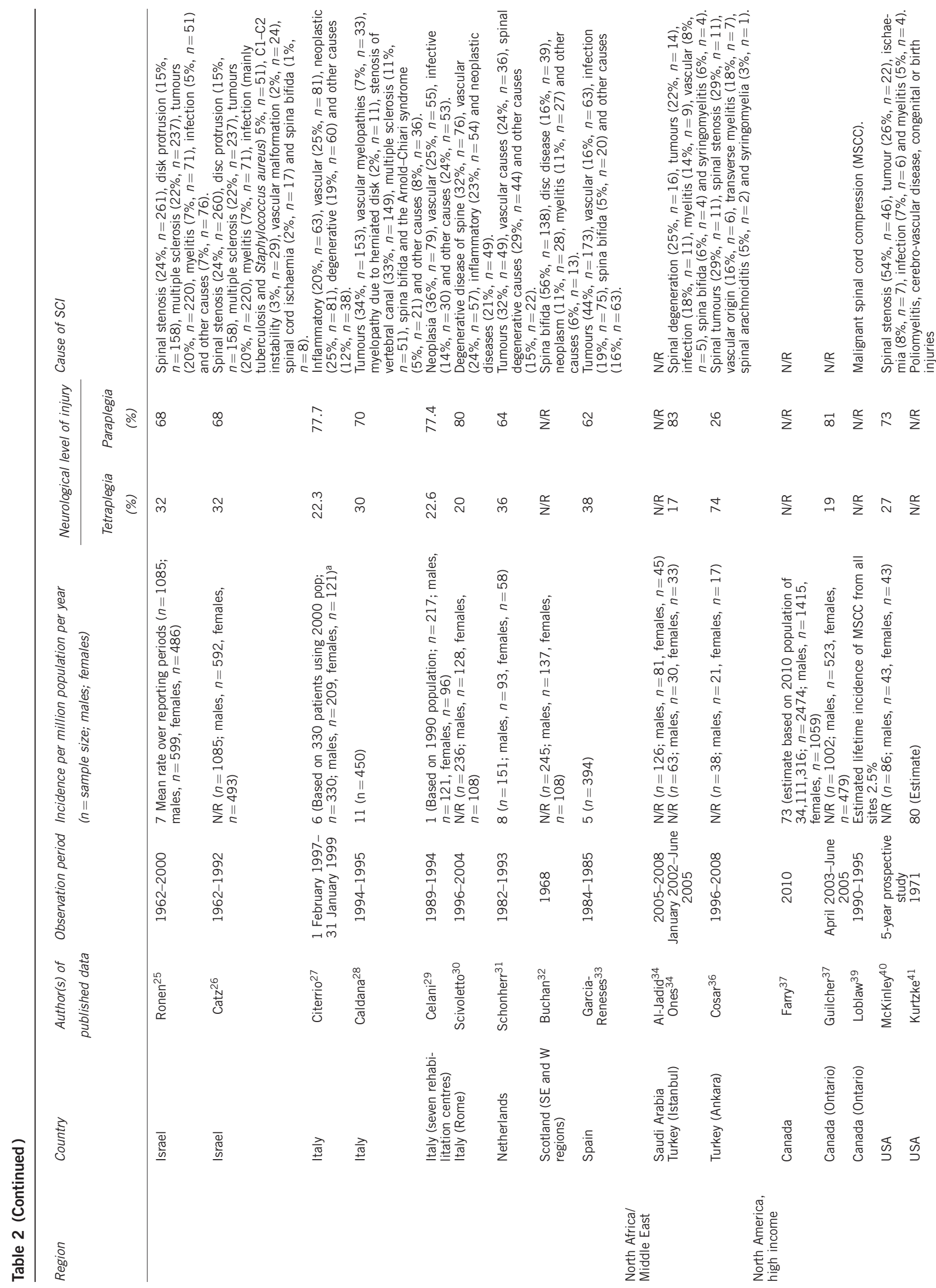




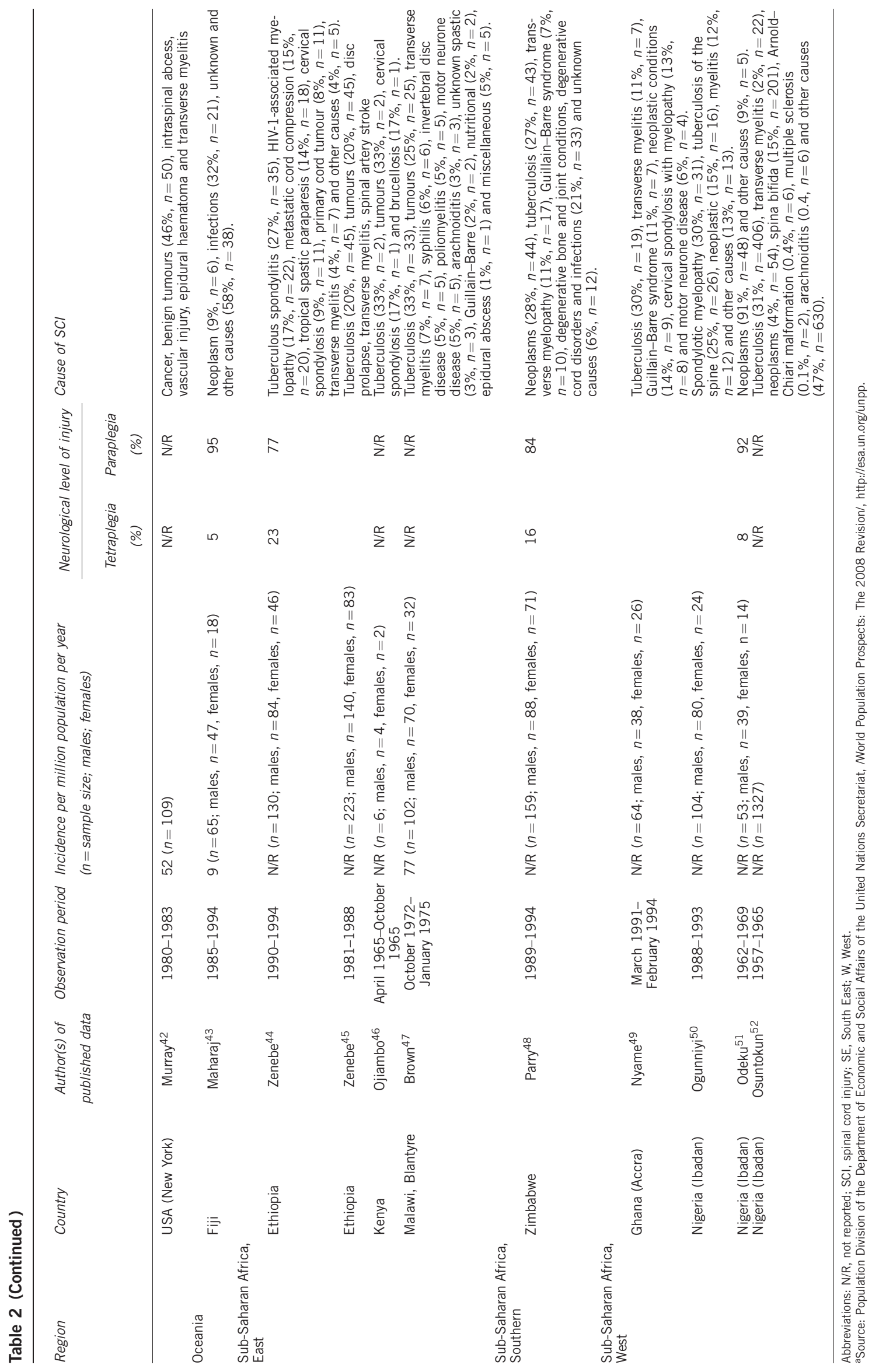




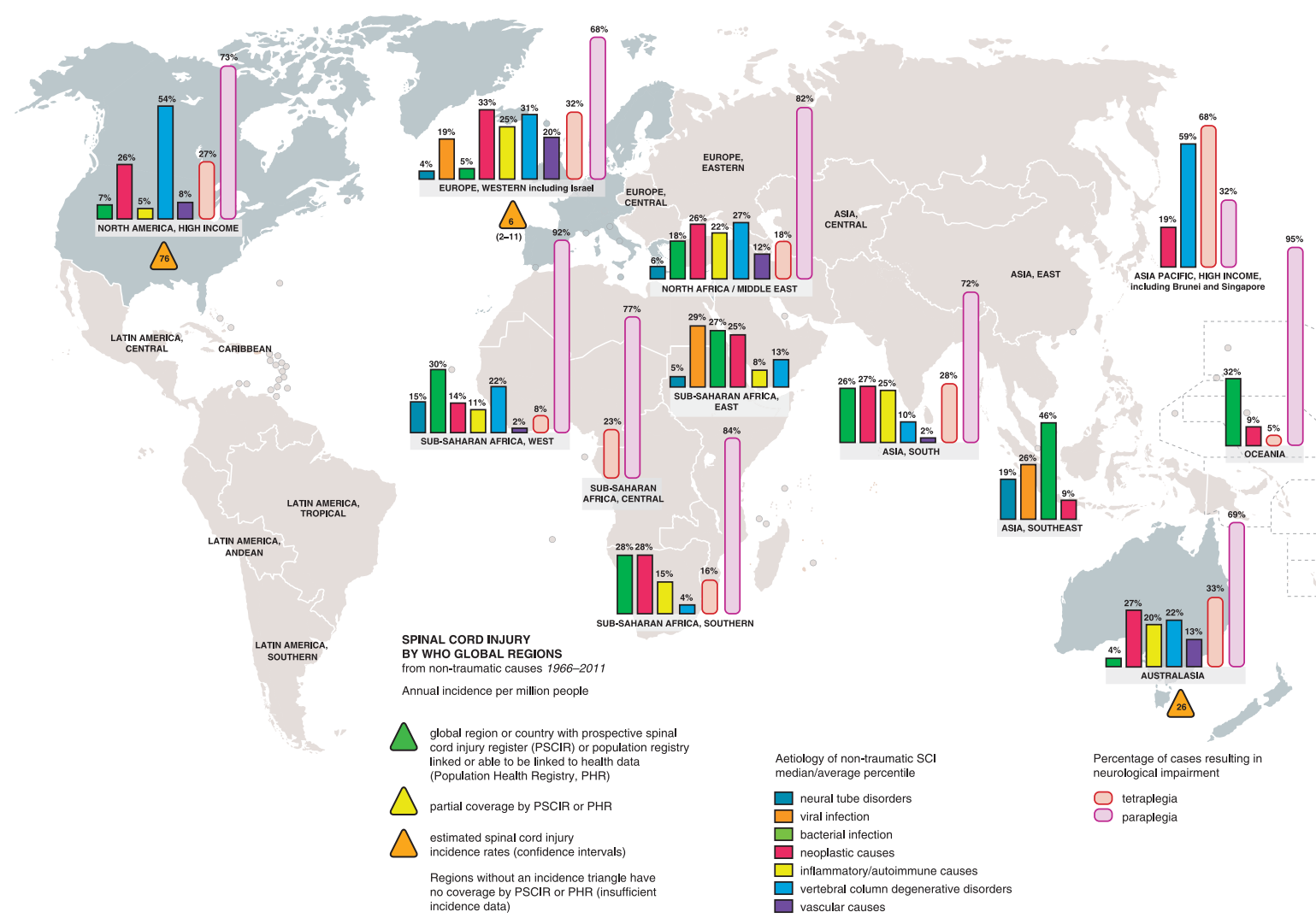

Figure 1 Global maps of NTSCl epidemiological outcomes (1959-2011) by WHO global regions.

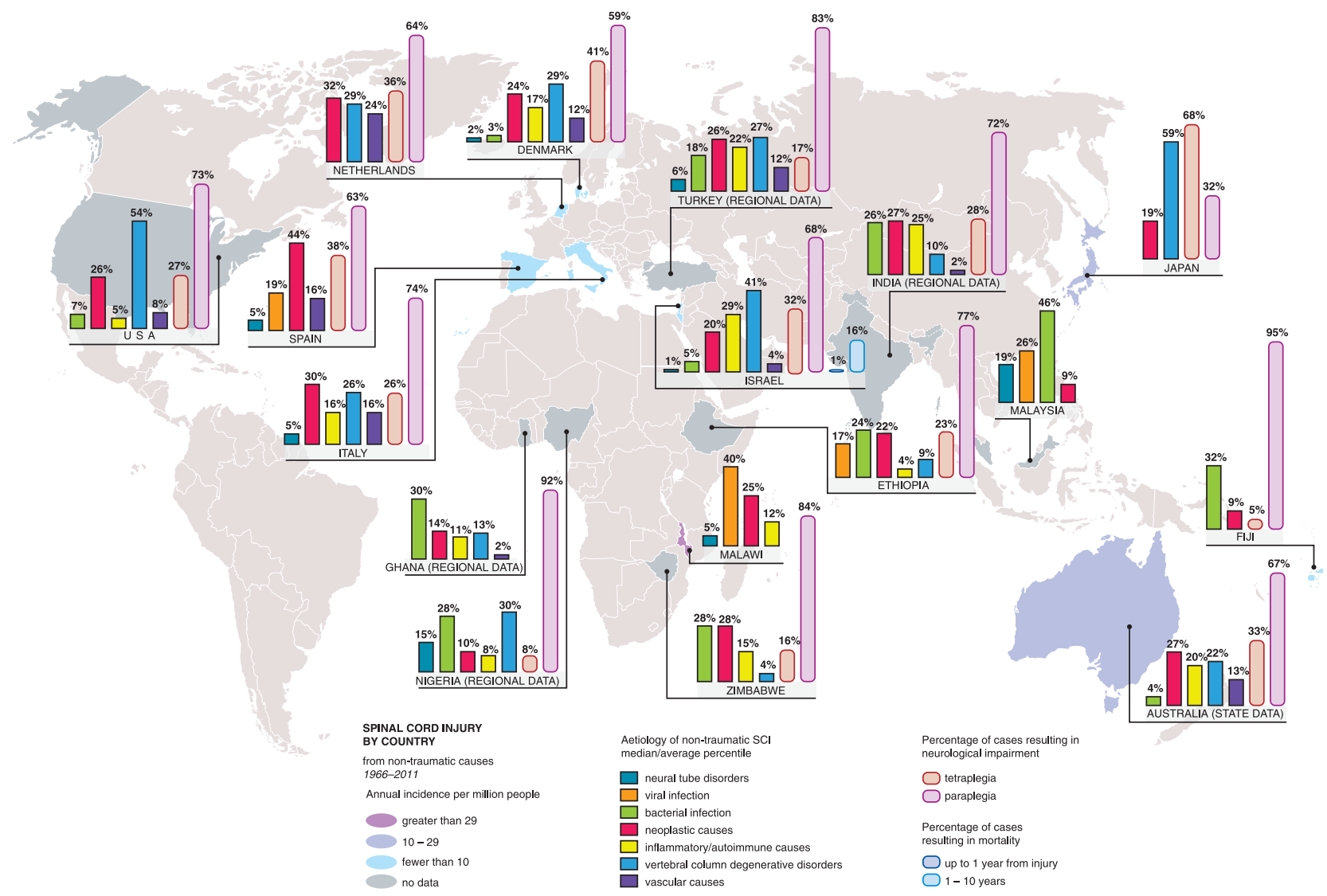

Figure 2 Global maps of NTSCI epidemiological outcomes (1959-2011) by country. 
Table 3 Prevalence of non-traumatic spinal cord injury by region and author(s) of published data

\begin{tabular}{llccc}
\hline Region & Country & Author(s) of published data & $\begin{array}{c}\text { Observation } \\
\text { period }\end{array}$ & Prevalence per million population \\
\hline Asia, South & India (Kashmir) & Razdan ${ }^{53}$ & 1986 & $\begin{array}{l}2310 \text { (poliomyelitis 2180/million and Potts's paraplegia, hereditary } \\
\text { spastic paraplegia and 'others' 126/million) prevalence rate based } \\
\text { on } 1986 \text { population of 63645; } n=147 \text { ) }\end{array}$ \\
North America, high income & Canada & Rick Hansen SCI Register ${ }^{37}$ & 2010 & 1120 (extrapolated from Australian data). ${ }^{16}$ \\
\hline
\end{tabular}

national or regional reporting is routinely occurring using internationally accepted data standards through an adequately resourced registry. The absence of national reporting, illustrated by the 'Red Zone' areas in the global maps, makes it difficult to determine valid population denominators.

Using the methods outlined by Fitzharris et al., ${ }^{55}$ it could be possible to extrapolate data to appropriate regions and to adjust for variables, such as socio-economic development, which influence NTSCI. NTSCI data are currently inadequate for this approach. This emphasises the need, in planning future studies, for quality national or regional data that may be used to contribute to global estimates of NTSCI incidence and prevalence.

In any epidemiological study of NTSCI, incidence or prevalence will be influenced by many factors. These factors have not been well studied to date. It is suggested that these include the following: underlying population characteristics (age distribution and genetic factors); regional disease patterns (especially infectious diseases and cancer); socio-economic and geographic factors; health systems resources and models of care (for example, medical diagnostics and management, and availability of acute hospital, rehabilitation and long-term follow-up); the range of readily accessible disability services within each region; and local referral patterns.

\section{Proposed research framework for the prevention of NTSCI and improving survival}

There are a range of health-care management strategies that could potentially reduce the incidence of and improve the survival following NTSCI. Given the relevance of prevention to incidence and survival, we propose the following approaches for preliminary consideration:

- Care for patients with degenerative conditions of the spinal column causing myelopathy ideally includes access to appropriate radiology and surgery for treatment where there is canal compromise causing significant symptomatic cord compression. Better-quality studies are required comparing conservative management with surgery in order to optimise management decision making. ${ }^{56,57}$

- For patients with suspected spinal tumours, ideal clinical care requires prompt access to magnetic resonance imaging and other diagnostic investigations. Secondary malignant tumours require surgery and radiotherapy to reduce the progression from bony lesions to symptomatic NTSCI and to limit the severity of the neurological impairment, especially within the first $48 \mathrm{~h} .{ }^{58}$ Chemotherapy is also sometimes indicated to improve the survival and cure prospects, especially for primary tumours, but also some secondary malignancies.

- Infections causing NTSCI require prompt access to radiological imaging, neurosurgery in some cases, and appropriate antibiotic, antiviral or antiparasitic treatments, as indicated. ${ }^{59,60}$
- NTSCI due to spinal vascular conditions require emergency access to radiological imaging and neurosurgery or specialist interventional radiology to optimise outcomes. ${ }^{60}$ In cases of NTSCI due to infarction, there is often little that can be done. Improved vascular surgery techniques, such as endo-luminal stenting of abdominal aortic aneurysms instead of open repair, may reduce the occurrence of cord infarction; however, evidence is currently inconclusive. ${ }^{61}$

- Folic acid prevents neural tube defects, including spina bifida, ${ }^{62}$ but is probably suboptimally utilised in many countries, especially developing countries.

A few aspects of the models of care for NTSCI management can potentially influence NTSCI survival, and therefore prevalence. Following the acute phase after onset of NTSCI in many settings, patients have suboptimal access to specialist SCI rehabilitation, despite experts in rehabilitation recommending such access ${ }^{15}$ and evidence of suboptimal outcomes when people with NTSCI are not able to access this expertise. ${ }^{63,64}$ Better follow-up after discharge from hospital following acute care or rehabilitation is needed for NTSCI patients. This should include life-long monitoring, prevention and treatment of complications related to NTSCI and risk reduction strategies for potential medical conditions or existing comorbid diseases that increase the risk or mortality in NTSCI patients (for example, cardiovascular diseases and obesity).

There is a paucity of publication on the prevention of NTSCI and improving survival. The suggestions proposed here are a starting framework for research and possible application.

\section{Limitations}

A limitation of this project is that there is a scarcity of quality research in the field of NTSCI epidemiology-highlighted by the absence of Green and Yellow information zones (Map 1). The scope and depth of information in most studies is scant. Furthermore, most studies are single-centre, with the potential for selection bias to influence the results. This applies especially to the aetiology of NTSCI and emphasises the need for state, or national population-based studies of incidence and outcome. Furthermore, there was no internationally accepted classification of NTSCI available at the time that the studies included in this review were carried out. This limited the ability to report and compare the aetiology of NTSCI across many countries and WHO regions.

There are major problems with some studies regarding the classification of the causes of NTSCI. These include in incidence studies the mixing of chronic NTSCI with new onset NTSCI patients when describing the study sample. For example, congenital and genetic cases are included with acute/subacute onset NTSCI patients. Furthermore, including multiple sclerosis in studies of NTSCI incidence or prevalence is problematic because lesions can occur in 
the brain or spinal cord. A case could be made for considering it a 'special case' of NTSCI, and reporting data separately. Some studies included conditions that do not actually constitute NTSCI. These include Guillain-Barré Syndrome (a lower motor neurone condition) and 'hysteria' (conversion disorders).

\section{Future directions}

More robust studies of the incidence, prevalence and survival of NTSCI are required. We have a number of recommendations for improving the quality of epidemiological studies of NTSCI that would result in more accurate, relevant and usable information for informing health planning and prevention strategies. We propose that the following standards be followed to improve the quality of research data in future studies of the incidence, prevalence and survival of NTSCI:

1. Authors should provide a clear description of their study sample(s). It is essential that a distinction be made between recent onset NTSCI cases that are newly diagnosed from those that are chronic.

2. Population-based study designs should be used where incidence and prevalence studies are carried out, especially in well-resourced countries.

3. Data should be reported using International Standards for reporting results of studies and data analysis. ${ }^{65}$

4. NTSCI aetiology should be described using the International NTSCI Data Sets, which includes a standardised classification system. ${ }^{8}$

5. Survival studies of NTSCI patients would help estimate prevalence and help plan for future health-care needs.

6. Ideally, annual reports of national statistics should be published on the internet in a searchable manner.

7. ISCoS and other relevant organisations should explore options for a centralised data repository and/or related links to national registries that together would function as a centralised data repository in order to facilitate NTSCI prevention efforts. The tabulations and a summary form for data submissions are available on the ISCoS website as part of the Global Mapping project (http://iscos.org.uk/page.php?content=67). We welcome submissions of unpublished or published data from the ISCoS readership and aim to produce regular updates for the ISCoS Prevention Committee and community.

\section{CONCLUSIONS}

Mapping techniques can allow complex data to be interpreted quickly and intuitively by clinicians and policy makers. Incorporation of epidemiological data regarding NTSCI into a central data repository, assessing the quality and determination of a course of action aimed at reducing NTSCI incidence or improve survival can benefit from mapping techniques. Future efforts of NTSCI researchers should address deficiencies identified here in order to improve the quality, quantity and comparability of available information. It is hoped that eventually research could extend to comparison of prevention methodology and allow more rapid global learning about what works and why, as well as provide policy support for advocates of NTSCI prevention.

\section{CONFLICT OF INTEREST}

The authors declare no conflict interest.

\section{ACKNOWLEDGEMENTS}

We acknowledge the members of the ISCoS Prevention Committee and the ISCoS membership for their continuing enthusiasm. Dr Lee and the Myriad Mapping were funded by the Prince of Wales Hospital Training, Education and Study Leave (TESL) Fund (New South Wales Department of Health, Australia).

1 Adams R, Salam-Adams M. Chronic nontraumatic diseases of the spinal cord. Neurol Clin 1991; 9: 605-623

2 Dawson D, Potts F. Acute nontraumatic myelopathies. Neurol Clin 1991; 9: 585-602.

3 New PW, Sundararajan V. Incidence of non-traumatic spinal cord injury in Victoria, Australia: a population-based study and literature review. Spinal Cord 2008; 46 406-411.

4 Cripps R, Lee B, Wing P, Weerts E, Mackay J, Brown D. A global map for traumatic spinal cord injury epidemiology: towards a living data repository for injury prevention. Spinal Cord 2011; 49: 493-501.

5 Wyndaele M, Wyndaele JJ. Incidence, prevalence and epidemiology of spinal cord injury: what learns a worldwide literature survey? Spinal Cord 2006; 44: 523-529.

6 Lee BB, Cripps RA, Fitzharris M, Wing PC. The global map for traumatic spinal cord injury epidemiology: update 2011, global incidence rate. Spinal Cord 2014; 52 110-116.

7 Harvard University, Institute for Health Metrics and Evaluation at the University of Wasington, Johns Hopkins University, University of Queensland, World Health Organization (WHO). Operations Manual, final draft, 20 January 2009.

8 New PW, Marshall R. International Spinal Cord Injury Data Sets for non-traumatic spinal cord injury. Spinal Cord 2014; 52: 123-132.

9 Ide M, Ogata H, Tokuhiro A, Takechi H. Spinal cord injuries in Okayama Prefecture: an epidemiological study '88-'89. J UOEH 1993; 15: 209-215.

10 Nair K, Taly A, Maheshwarappa B, Kumar J, Murali T, Rao S. Nontraumatic spinal cord lesions: a prospective study of medical complications during in-patient rehabilitation. Spinal Cord 2005; 43: 558-564.

11 Agarwal P, Upadhyay P, Raja K. A demographic profile of traumatic and non-traumatic spinal injury cases: a hospital-based study from India. Spinal Cord 2007; 45 597-602.

12 Gupta A, Taly AB, Srivastava A, Murali T. Non-traumatic spinal cord lesions: epidemiology, complications, neurological and functional outcome of rehabilitation. Spinal Cord 2009; 47: 307-311.

13 Bhaskar P, Arjundas G, Ramamurthi B. Acute non-traumatic paraplegia. J Assoc Physicians India 1972; 20: 687-691.

14 Silva JF. Some experiences with non-traumatic paraplegia in Malaysia. Paraplegia 1973; 11: 146-158.

15 New PW. Non-traumatic spinal cord injury: what is the ideal setting for rehabilitation? Aust Health Rev 2006; 30: 353-361.

16 New PW, Simmonds F, Stevermuer T. A population-based study comparing traumatic spinal cord injury and non-traumatic spinal cord injury using a national rehabilitation database. Spinal Cord 2011; 49: 397-403.

17 New PW, Rawicki HB, Bailey MJ. Nontraumatic spinal cord injury: Demographic characteristics and complications. Arch Phys Med Rehabil 2002; 83: 996-1001.

$18 \mathrm{New}$ P. Functional outcomes and disability after nontraumatic spinal cord injury rehabilitation: results from a retrospective study. Arch Phys Med Rehabil 2005; 86 250-261

19 Burke DC, Burley HT, Ungar GH. Data on spinal injuries - Part 1. Collection and analysis of 352 consecutive admissions. Aust NZ J Surg 1985; 55: 3-12.

20 Penington GR. Management of non-traumatic paraplegia. Med J Aust 1986; 144 364-365.

21 Cheshire DJE. The Complete and Centralized Treatment of Paraplegia: A Report on the Spinal Injuries Centre for Victoria, Australia. National Institute for Neurological Diseases Workshop: Melbourne, Victoria, 1966

22 Biering-Sorensen F, Pedersen V, Clausen S. Epidemiology of spinal cord lesions in Denmark. Paraplegia 1990; 28: 105-108.

23 Minaire P, Castanier M, Girard R, Berard E, Deidier C, Bourret J. Epidemiology of spina cord injury in the Rhone-Alpes Region, France, 1970-75. Paraplegia 1978-79; 16 76-87.

24 Exner G, Meinecke FW. Trends in the treatment of patients with spinal cord lesions seen within a period of 20 years in German centers. Spinal Cord 1997; 35: 415-419.

25 Ronen J, Goldin D, Bluvshtein V, Fishel B, Gelernter I, Catz A. Survival afte nontraumatic spinal cord lesions in Israel. Arch Phys Med Rehabil 2004; 85: 1499-1502.

26 Catz A, Goldin D, Fishel B, Ronen J, Bluvshtein V, Gelernter I. Recovery of neurologic function following nontraumatic spinal cord lesions in Israel. Spine 2004; 29 2278-2282.

27 Citterio A, Franceschini M, Spizzichino L, Reggio A, Rossi B, Stampacchia G. Nontraumatic spinal cord injury: an Italian survey 1. Arch Phys Med Rehabil 2004, 85: 1483-1487.

28 Caldana L, Lucca L. Epidemiological remarks on traumatic spinal cord injuries and non-traumatic spinal cord diseases in Veneto 1994-1995. Eur Med Phys 1998; 34 159-168.

29 Celani MG, Spizzichino L, Ricci S, Zampolini M, Franceschini M. Spinal cord injury in Italy: a multicenter retrospective study. Arch Phys Med Rehabil 2001; 82: 589-596. 
30 Scivoletto G, Farchi S, Laurenza L, Molinari M. Traumatic and non-traumatic spinal cord lesions: an Italian comparison of neurological and functional outcomes. Spinal Cord 2011; 49: 391-396.

31 Schonherr MC, Groothoff JW, Mulder GA, Eisma WH. Rehabilitation of patients with spinal cord lesions in the Netherlands: an epidemiological study. Spinal Cord 1996; 34: 679-683.

32 Buchan AC, Fulford GE, Harris P, Jellinek E, Kerr WG, Kirkland I et al. A preliminary survey of the incidence and aetiology of spinal paralysis. Paraplegia 1972; 10: 23-28.

33 Garcia-Reneses J, Herruzo-Cabrera R, Martinez-Moreno M. Epidemiological study of spinal cord injury in Spain 1984-1985. Paraplegia 1991; 29: 180-190.

34 Al-Jadid MS, Asirvatham RA. An analysis of the length of stay in traumatic and nontraumatic spinal cord injured patients. Saudi Med J 2010; 31: 555-559.

35 Ones K, Yilmaz E, Beydogan A, Gultekin O, Caglar N, Ones K et al. Comparison of functional results in non-traumatic and traumatic spinal cord injury. Disabil Rehabil 2007; 29: 1185-1191.

36 Cosar S, Yemisci O, Oztop P, Cetin N, Sarifakioglu B, Yalbuzdag S et al. Demographic characteristics after traumatic and non-traumatic spinal cord injury: a retrospective comparison study. Spinal Cord 2010; 48: 862-866.

37 Farry A, Baxter D. The Incidence and Prevalence of Spinal Cord Injury in Canada: Overview and estimates based on current evidence. Rick Hansen Institute and Urban Futures Institute 2010

38 Guilcher SJ, Munce SE, Couris CM, Fung K, Craven BC, Verrier M et al. Health care utilization in non-traumatic and traumatic spinal cord injury: a population-based study. Spinal Cord 2010; 48: 45-50.

39 Loblaw DA, Laperriere NJ, Mackillop WJA. Population-based study of malignant spinal cord compression in Ontario. Clin Oncol 2003; 15: 211-217.

40 McKinley WO, Seel R, Hardman J. Non traumatic spinal cord injury: incidence, epidemiology, and functional outcome. Arch Phys Med Rehabil 1999; 80: 619-623.

41 Kurtzke JF. Epidemiology of spinal cord injury. Exp Neurol 1975; 48(3, Part 2): 163-236.

42 Murray PK, Kusior MF. Epidemiology of nontraumatic and traumatic spinal cord injury. Arch Phys Med Rehabil 1984; 65: 634.

43 Maharaj JC. Epidemiology of spinal cord paralysis in Fiji: 1985-1994. Spinal Cord 1996; 34: 549-559.

44 Zenebe G. Myelopathies in ethiopia. East Afr Med J 1995; 72: 42-45.

45 Zenebe G, Oli K, Tekle-Haimanot R. Paraplegia at the Tikur Anbessa Teaching Hospital: a seven year retrospective study of 164 cases. Ethiop Med J 1995; 33: 7-13.

46 Ojiambo HP. Neurological disease at Kenyatta National Hospital, Nairobi. East Afr Med J 1966; 43: 366-376.

47 Brown KGE. Non-traumatic paraplegia in sub-saharan Africa. East Afr Med J 1979; 56: 300-310.

48 Parry O, Bhebhe E, Levy LF. Non-traumatic paraplegia in a Zimbabwean population-a retrospective survey. Cent Afr J Med 1999; 45: 114-119.
49 Nyame P. An aetiological survey of paraplegia in Accra. East Afr Med J 1994; 71: 527-530.

50 Ogunniyi A, Shokunbi M, Oluwole O, Adeyinka A, Malomo A, Adebiyi A. Non-traumatic spinal cord diseases in Ibadan, Nigeria: aetiology and prognostic factors. Cent Afr J Med, 1995; 41: 50-54

51 Odeku LE, Adeloye A, Osuntokun BO. Non-tuberculous intraspinal canal masses in Ibadan. Afr J Med Sci 1971; 2: 37-48.

52 Osuntokun BO. The pattern of neurological illness in tropical Africa: Experience at Ibadan, Nigeria. J Neurol Sci 1970; 12: 417-442.

53 Razdan S, Kaul RL, Motta A, Kaul S, Bhatt RK. Prevalence and pattern of major neurological disorders in rural Kashmir (India) in 1986. Neuroepidemiology 1994; 13: 113-119.

54 Exner G, Meinecke F-W. Trends in the treatment of patients with spinal cord lesions seen within a period of 20 years in German centers. Spinal Cord 1997; 35: 415-419.

55 Fitzharris M, Cripps RA, Lee BB. Estimating the global burden of traumatic spinal cord injury. Spinal Cord 2014; 52: 117-122.

56 Harrop JS, Hanna A, Silva MT, Sharan A. Neurological manifestations of cervical spondylosis: an overview of signs, symptoms, and pathophysiology. Neurosurgery 2007; 60: S14-S20.

57 Vanichkachorn JS, Vaccaro AR. Thoracic disk disease: diagnosis and treatment. J Am Acad Orthop Surg 2000; 8: 159-169.

58 National Institute for Health and Clinical Excellence. Metastatic spinal cord compression: diagnosis and management of patients at risk of or with metastatic spinal cord compression. (Clinical guideline 75.) www.nice.org.uk/CG75 2008.

59 Quiñones-Hinojosa A, Jun P, Jacobs R, Rosenberg WS, Weinstein PR. General principles in the medical and surgical management of spinal infections: a multidisciplinary approach. Neurosurg Focus 2004; 17: E1.

60 Wang VY, Chou D, Chin C. Spine and spinal cord emergencies: vascular and infectious causes. Neuroimaging Clin N Am 2010; 20: 639-650.

61 Lederle FA, Freischlag JA, Kyriakides JA, Padberg Jr FT, Matsumura JS, Kohler TR et al. Outcomes following endovascular vs open repair of abdominal aortic aneurysm a randomized trial. JAMA 2009; 302: 1535-1542.

62 Lumley J, Watson L, Watson M, Bower C. Periconceptional supplementation with folate and/or multivitamins for preventing neural tube defects. Cochrane Database Syst Rev 2001, Art. No.CD001056 doi:10.1002/14651858.CD001056.

63 New PW, Simmonds F, Stevermuer T. Comparison of patients managed in specialised spinal rehabilitation units with those managed in non-specialised rehabilitation units. Spinal Cord 2011; 49: 909-916.

64 Smith M. Efficacy of specialist versus non-specialist management of spinal cord injury within the UK. Spinal Cord 2002; 40: 11-16.

65 DeVivo MJ, Biering-Sorensen F. Standardization of data analysis and reporting of results from the International Spinal Cord Injury Core Data Set. Spinal Cord 2010; 49: 596-599. 